\title{
Correspondence
}

\section{Evaluating treatment outcomes}

\section{DeAR SIRS}

There is evidence from both research and clinical studies which stresses the importance of evaluating treatment outcomes, possibly through the measurement of social role functioning. We report a proposal to apply these research findings in a brief instrument to measure role performance, requiring a minimum time to complete.

Social role performance as an outcome takes into account the major impact which psychiatric illness has on the sufferer as well as on those family and community members who have close or regular contact with the patient. It is meaningful when used in conjunction with other assessments of treatment outcome, e.g. the level of symptomatology, and should not be seen as an alternative single measure of outcome.

Attempts to measure social role performance extended back some 30 years; however, the usefulness of the measure has been limited by the problem that performance of social roles is governed to a large extent by social and cultural norms, which will vary over time and circumstances. These are identifiable in the form of expectations held by relatives or significant others as to which roles should be performed. The Social Behaviour Assessment Schedule (Platt et al, 1980) is a recent instrument for the assessment of role performance which specifically recognises these limitations by allowing non-completion of social role items that are inapplicable.

Extensive use of this schedule in two major studies (Creed et al, 1989, 1990) and subsequent statistical analyses using multivariate techniques (Anthony, 1989) have suggested that it is possible to develop a brief instrument, capable of measuring social role performance on a routine basis and concentrating on critical everyday role items. Some of the criteria for this brief instrument include that it should be limited to a maximum of 20 items, it should be available in two formats, a self report and an informant report version, and it should be simple and quick to complete. A third format for completion by the clinician would provide an additional source of information.

A brief instrument encompassing the above criteria has been written and we propose to conduct a validation study of this new instrument. We aim to identify whether the new questionnaire is sensitive to changes in a patient's role performance, and whether it elicits a similar response pattern to that seen in the parent instrument. The study will be multi- centred, involving approximately ten consultant psychiatrists, interviewing patients and informants on admission and at follow-up, approximately three months later. A sample of informants will also be interviewed using the original SBAS. All adult psychiatric patients referred with a diagnosable illness will be interviewed, excluding alcohol and drug dependency categories, whether managed as in-, out- or day-patients. Evaluation of the results will be carried out and the results made available to the psychiatric community.

Comments or suggestions from anyone interested would be very gratefully received.

\section{Gateway House \\ Piccadilly South \\ Manchester M60 7LU}

Phil Anthony

Malham House

25 Hyde Terrace

Leeds 2

\section{References}

Anthony, P. (1989) Validity of informant reports in psychiatry. PhD Thesis, Department of Psychiatry, Manchester University.

Creed, F. H., Anthony, P., Godbert, K. \& Huxley, P. (1989) Treatment of severe psychiatric illness in a day hospital. British Journal of Psychiatry, 154, 341-347.

- Black, D., ANTHony, P., Osborn, M., Thomas, P. \& Tomenson, B. (1990) Randomised controlled trial of day patient versus inpatient psychiatric treatment. British Medical Journal, 300, 1033-1037.

Platt, S., Weyman, A., Hirsch, S. \& Hewett, S. (1980) The Social Behaviour Assessment Schedule SBAS: Rationale, Contents, Scoring and Reliability of a New Interview Schedule. Social Psychiatry, 15, 43-55.

\section{What are the necessary qualities of a senior registrar in psychiatry?}

DeAR SIRS

'If a man was called a Scientist during his lifetime and an Honoured one at that, it was the end of him as a doctor. The honour and glory of it would get in the way of his treatment of his patients, just as elaborate clothing hinders a man's movements.' Solzhenitsyn, A. (1971, Cancer Ward. London: The Bodley Head; Harmondsworth: Penguin.) 